\title{
Association between job characteristics and plasma fibrinogen in a normal working population: a cross sectional analysis in referents of the SHEEP study
}

\author{
Akizumi Tsutsumi, Töres Theorell, Johan Hallqvist, Christina Reuterwall, Ulf de Faire
}

Department of Environmental Medicine, Kurume University School of Medicine, Kurume, 8300011, Japan

A Tsutsumi

Swedish National Institute for Psychosocial Factors and Health, Karolinska Institutet, and the Departments of Occupational Health and Psychosocial Factors, Department of Public Health Sciences, Karolinska Institutet, Stockholm, Sweden

$\mathrm{T}$ Theorell

Division of Social Medicine at the Department of Public Health Sciences, Karolinska Institutet, Stockholm, Sweden J Hallqvist

National Institute of Occupational Health, and the Department of Occupational Health, Karolinska Hospital, and the Institute of

Environmental Health, Karolinska Institute, Stockholm, Sweden

C Reuterwall

Division of

Cardiovascular

Epidemiology,

Institute of

Environmental

Medicine, Karolinska

Institute, Stockholm,

Sweden

U de Faire

Correspondence to:

Dr A Tsutsumi.

Accepted for publication 8 December 1998

\begin{abstract}
Study objective-To explore the association between job characteristics and plasma fibrinogen concentrations. Design-Cross sectional design.

Setting-The Greater Stockholm area. Subjects-A total of 1018 men and 490 women aged 45-70 who were randomly selected from the general population during 1992-1994. They were all employed and had no history of myocardial infarction.
\end{abstract}

Main results-The self reported job characteristics were measured by a Swedish version of the Karasek demand-control questionnaire. For inferred scoring of job characteristics, psychosocial exposure categories (job control and psychological demands) were assigned by linking each subject's occupational history with a work organisation exposure matrix. Job strain was defined as the ratio between demands and control. In univariate analyses, expected linear trends were found in three of four tests of association between high plasma fibrinogen and low control (the self reported score for women and the inferred score for both sexes), in one of four tests of association between high plasma fibrinogen and high demands (the inferred score for women) and in two of four tests of association between high plasma fibrinogen and job strain (the inferred score for both sexes). Multiple logistic regression analyses showed that men in the inferred job strain group have an increased risk of falling into the increased plasma fibrinogen concentration group (above median level of the distribution) (odds ratio (OR) $1.2 ; 95 \%$ CI $1.0,1.5)$ after adjustment for the variables that were associated with plasma fibrinogen in the univariate analyses. In women, low self reported control, high inferred demand, and inferred job strain were significantly associated with increased plasma fibrinogen concentration (OR 1.3; 95\% CI $1.0,1.8$, OR $1.5 ; 95 \%$ CI $1.0,2.2$, OR 1.5; 95\% CI 1.1, 2.2, respectively).

Conclusions-These results indicate that adverse job characteristics may be related to plasma fibrinogen concentrations and this relation is more relevant in female workers. The clearest evidence for psychosocial effects on plasma fibrinogen seems to be with job control and the asso- ciations are clearer for the objective than for the self report variables.

(F Epidemiol Community Health 1999;53:348-354)

There is increasing interest in the contribution of plasma fibrinogen to coronary heart disease (CHD) risk. Epidemiological cohort studies ${ }^{1-4}$ suggest that plasma fibrinogen is an independent risk factor for CHD. As evidence accumulates to implicate plasma fibrinogen in the pathogenesis of CHD, it becomes important to examine what factors may determine plasma fibrinogen concentrations.

Job related stress is considered as a potentially important factor in the development of cardiovascular disease (CVD). Increased plasma fibrinogen has been indicated as one of the possible mechanisms of job stress leading to CVD. ${ }^{5}$ Friedman et $a l^{6}$ showed that blood clotting time was accelerated when workers suffered qualitative occupational stress. Netterstrøm et $a l^{7}$ and Folsom et $a l^{8}$ have shown a tendency towards high plasma fibrinogen concentrations in the high strain (low control and high psychological demands at work) group. Davis et $a l^{9}$ indicated that female workers who perceived high job stress or low support from their boss had increased plasma fibrinogen concentrations, independently of menopausal status. Markowe et $a l^{10}$ have shown that control over the work is inversely related to plasma fibrinogen concentrations and recently Brunner and his colleagues ${ }^{11}$ have confirmed the association in a larger sample of the British civil servants. However, there are several studies showing negative results and even those with results in the opposite direction. ${ }^{12-14}$

The inconsistency of these results may be attributable to the differences in the study sampling and methodology. Ishizaki et $a l,{ }^{14}$ Mattiasson and Lindgärde, ${ }^{13}$ and Møller and Kristensen ${ }^{12}$ found no association between job strain and plasma fibrinogen concentrations. All their subjects were male workers, and except for the study population of Møller and Kristensen they were derived from a single factory. In contrast, Netterstrøm et al, ${ }^{7}$ Folsom et $a l^{8}$ and Davis et al could see positive findings in their respective representative populations. Brunner et $a l^{11}$ also studied a sample from a wide range of occupations of the British civil servants. Furthermore in many previous studies, the job characteristics were measured only by means of a self report questionnaire. Brunner $e t a l^{11}$ showed clear relations between expert 
rated job control (assessed by personal managers) and plasma fibrinogen concentrations, however. To study a broad range of occupations may make it possible to evaluate wider variance of occupational stress and measuring job characteristics by means of both subjective and objective methods could give us further insight regarding job stress and plasma fibrinogen relations. As a sex difference in the association is suspected, ${ }^{9}$ it would be meaningful to perform separate analyses for women and men.

As part of a large scale, multidisciplinary, case-referent study, SHEEP (Stockholm Heart Epidemiology Program), of all first myocardial infarctions in the greater Stockholm area during a three year period, we aimed at studying the relation between plasma fibrinogen and job characteristics. In addition, the influence of both subjectively and more objectively evaluated job characteristics on plasma fibrinogen concentrations were assessed to test the hypothesis; adverse job characteristics - such as low control over the work, high psychological demands, and high job strain that is the combination of low control and high demands - are positively associated with high plasma fibrinogen concentrations.

\section{Methods}

SUBJECTS

SHEEP is a population based case-referent study of risk factors for myocardial infarction, first episode. The study design and the total study population are described elsewhere..$^{15}$ As our special interest was in the association between job characteristics and plasma fibrinogen in a general population, this analysis has been confined to the referents of the non-fatal cases in the SHEEP study. The SHEEP study base comprised all Swedish citizens resident in the Stockholm county, who were free of previously diagnosed myocardial infarction. Male cases were identified during two years (19921993), and female cases during three years (1992-1994). Through October 1992, the study base included the ages 45-65 years; from 1 November 1992 and onwards, the age span was $45-70$ years. Fatal, as well as non-fatal cases were included. One referent per case was randomly selected from the study base after stratification for sex, age, and hospital catchment area at the case incidence. To obtain a responding referent for each identified case, a new referent was selected if the first one did not participate. Therefore more referents than cases were finally included. This does not affect the calculated participation rate, which is based upon the total number of people who were invited to participate. Exposure information was collected by an extensive questionnaire and a health examination including blood sampling. Among the referents, the health examination was confined to those of the non-fatal cases. The study participation rate among the referents of non-fatal cases was $75 \%$ for men and $69 \%$ for women. A number of plasma samples were lost because of a deep freezer break down; thus the study sample for this analysis comprised 1018 men and 490 women, for whom questionnaire exposure information as well as plasma fibrinogen results were available. The study has been approved by the Regional Ethics Committee of the Karolinska Institute, Stockholm, Sweden.

\section{PROCEDURE}

The exposure information was collected by means of a comprehensive questionnaire and a health examination including blood sampling and several biological measurements. On the basis of responses to the questionnaire, marital status and educational level, respectively, were categorised (basic and higher levels for education). Women were asked about their menopausal status and use of hormone replacement therapy or intake of oral contraceptives.

Smokers were categorised into never, ex, and current smokers. Subjects who smoked when included in SHEEP, or had stopped smoking within the past two years before inclusion, were classified as current smokers. Alcohol intake in grams per day was based on self reported frequency, amount, and type of alcohol beverages normally consumed and subjects were grouped into three categories according to tertiles of alcohol intake; never or minimal drinking (consumed alcohol $<4.8 \mathrm{~g} /$ day), moderate drinking (consumed alcohol $\leqslant 4.8 \mathrm{~g} /$ day, $<15.5 \mathrm{~g} /$ day; nearly equal two glasses of wine), and heavy drinking (consumed alcohol $\leqslant$ $15.5 \mathrm{~g} /$ day). Degree of physical activity was assessed according to leisure time habits. Those who were inactive or only occasionally took a walk were coded as exposed to physical inactivity and persons who exercised now and then or more (= at least once a week) were coded as active. We have assessed activity levels during the period 5-10 years before inclusion into SHEEP.

We also examined other factors previously shown to be associated with plasma fibrinogen concentrations, such as fish intake, ${ }^{17}$ coffee intake, ${ }^{18}$ and seasonal variation. ${ }^{19}$ Subjects who reported to have scarcely consumed fish or coffee were categorised separately. They were divided into two groups according to the time when blood samples were collected-winter (December to March) compared with the other seasons.

As for disease history, a subject was operationally defined as having hypertension when they reported a history of treatment of hypertension or had a high blood pressure level (systolic $\geqslant 170$ or diastolic $\geqslant 95$ ) in the supine position after five minutes of resting. The mean of the first and second readings was used in this study. History of diabetes mellitus was defined from the answers of the questionnaire. History of chest pain was also asked for, as was other cardiovascular diseases, such as stroke. Subjects were asked about the medical history of their family members, too.

With regard to occupational class, subjects were divided into white collar and blue collar workers by the Swedish SEI classification. ${ }^{20}$ We used information on occupation from the year before inclusion in SHEEP. A dichotomisation (blue/white collar) was considered to be the best way of dividing the sample because of the known non-linear relations in middle strata 
Table 1 Crude measures of job characteristics of the study subjects from referents of the SHEEP study, 1992-1994

\begin{tabular}{lrrrll}
\hline Variables & Number & Mean & SD & Minimum & Maximum \\
\hline Men & & & & & \\
$\quad$ Self reported control & 1000 & 18.26 & 2.80 & 7 & 24 \\
Self reported demand & 1001 & 11.39 & 2.82 & 5 & 20 \\
Self reported strain & 996 & 0.64 & 0.19 & 0.208 & 2.286 \\
Inferred control & 751 & 6.00 & 1.40 & 1.875 & 8.609 \\
Inferred demand & 751 & 5.32 & 1.64 & 0.714 & 9.285 \\
$\quad$ Inferred strain & 751 & 0.90 & 0.28 & 0.139 & 2.148 \\
Women & & & & & \\
Self reported control & 467 & 16.34 & 3.25 & 6 & 24 \\
Self reported demand & 468 & 10.83 & 3.01 & 5 & 19 \\
$\quad$ Self reported strain & 463 & 0.69 & 0.24 & 0.250 & 1.833 \\
Inferred control & 273 & 5.19 & 1.08 & 2.739 & 8.055 \\
Inferred demand & 273 & 4.89 & 1.47 & 0.500 & 8.750 \\
Inferred strain & 273 & 0.98 & 0.37 & 0.098 & 2.220 \\
\hline
\end{tabular}

between social class and morbidity in Swedish general population samples. ${ }^{21}$ Working conditions were also explored with regard to shift work - constant change in work hours according to fixed schedule (yes/no), frequent overtime work (yes/no) and night work - a substantial part of the working hours scheduled at night (yes/no). Subjects were also asked whether they served as supervisors or not.

Job characteristics were evaluated by self reported questionnaire and by means of inferred scoring. The self reported job characteristics classification is derived from a Swedish version of the Karasek demand-control questionnaire. ${ }^{22}$ The five questions regarding demands concern both qualitative and quantitative demandssuch as amount to do and conflicting demands. Cronbach's coefficient alpha for the psychological demands index was 0.74 for both male and female referent working populations. Questions measuring job control have two areas, one concerning skill discretion (four questions regarding such factors as variation and opportunity to use skill and learn new things) and one concerning authority over decisions (two questions regarding opportunity to influence what to do and how to do it at work). Cronbach's coefficient alpha for the control index was 0.66 for men and 0.65 for women. For inferred scoring of job characteristics, psychosocial exposure categories were assigned by linking each subject's occupational history with a work organisation exposure matrix. The matrix is based upon representative samples of the Swedish working population and average scores for job control and psychological demands are available for subgroups specified with regard to occupational title, sex, age as well as duration of employment. The job control scale is a 12 item indicator measuring decision authority and skill discretion on the job and the

Table 2 Geometric means and 95\% confidence intervals (CI) of plasma fibrinogen concentrations (g/l) according to sociodemographic and behavioural variables in referents of the SHEEP study, 1992-1994

\begin{tabular}{|c|c|c|c|c|c|c|c|c|c|}
\hline \multirow[b]{2}{*}{ Variables } & & \multicolumn{4}{|l|}{ Men } & \multicolumn{4}{|l|}{ Women } \\
\hline & & Number & Mean $(95 \% C I)$ & F ratio & $p$ & Number & Mean $(95 \% C I)$ & F ratio & $p$ \\
\hline \multirow[t]{3}{*}{ Age (y) } & $45-54$ & 305 & $3.19(3.12,3.27)$ & 17.335 & 0.0000 & 78 & $3.31(3.16,3.47)$ & 6.271 & 0.0020 \\
\hline & $55-64$ & 423 & $3.39(3.33,3.45)$ & & & 196 & $3.56(3.46,3.66)$ & & \\
\hline & $65-70$ & 290 & $3.51(3.43,3.59)$ & & & 216 & $3.64(3.54,3.74)$ & & \\
\hline \multirow{2}{*}{ Marital status } & Married & 832 & $3.34(3.29,3.38)$ & 5.916 & 0.0152 & 333 & $3.53(3.45,3.60)$ & 1.334 & 0.2487 \\
\hline & Not married & 172 & $3.48(3.38,3.58)$ & & & 148 & $3.61(3.48,3.74)$ & & \\
\hline \multirow[t]{2}{*}{ Education } & Higher & 336 & $3.23(3.17,3.30)$ & 18.869 & 0.0000 & 90 & $3.37(3.24,3.50)$ & 7.546 & 0.0062 \\
\hline & Basic & 682 & $3.43(3.37,3.48)$ & & & 400 & $3.59(3.52,3.67)$ & & \\
\hline \multirow[t]{2}{*}{ Menopausal status } & Premenopause & & & & & 56 & $3.22(3.04,3.41)$ & 15.499 & 0.0001 \\
\hline & Postmenopause & & & & & 428 & $3.60(3.54,3.67)$ & & \\
\hline \multirow[t]{2}{*}{ Hormone therapy } & Yes & & & & & 114 & $3.36(3.25,3.48)$ & 11.534 & 0.0007 \\
\hline & No & & & & & 373 & $3.62(3.54,3.69)$ & & \\
\hline \multirow[t]{2}{*}{ Contraceptive use } & No & & & & & 292 & $3.60(3.52,3.69)$ & 2.585 & 0.1086 \\
\hline & Yes & & & & & 191 & $3.49(3.39,3.60)$ & & \\
\hline \multirow[t]{3}{*}{ Smoking } & Never smoker & 355 & $3.25(3.18,3.32)$ & 26.890 & 0.0000 & 243 & $3.52(3.44,3.60)$ & 5.566 & 0.0041 \\
\hline & Ex smoker & 347 & $3.28(3.20,3.35)$ & & & 112 & $3.43(3.31,3.55)$ & & \\
\hline & Current smoker & 303 & $3.60(3.53,3.67)$ & & & 128 & $3.72(3.57,3.87)$ & & \\
\hline \multirow[t]{3}{*}{ Alcohol intake } & Never or minimal drinking & 245 & $3.40(3.32,3.48)$ & 1.710 & 0.1820 & 249 & $3.61(3.52,3.70)$ & 5.780 & 0.0033 \\
\hline & Moderate drinking & 324 & $3.30(3.23,3.38)$ & & & 173 & $3.56(3.46,3.67)$ & & \\
\hline & Heavy drinking & 436 & $3.38(3.32,3.45)$ & & & 61 & $3.28(3.10,3.47)$ & & \\
\hline \multirow[t]{2}{*}{ Physical activity } & Active & 668 & $3.30(3.25,3.35)$ & 18.897 & 0.0000 & 280 & $3.45(3.38,3.53)$ & 12.132 & 0.0005 \\
\hline & Inactive & 332 & $3.49(3.42,3.57)$ & & & 200 & $3.68(3.58,3.79)$ & & \\
\hline \multirow[t]{2}{*}{ Fish intake } & Yes & 433 & $3.31(3.25,3.37)$ & 4.743 & 0.0297 & 250 & $3.57(3.48,3.66)$ & 0.268 & 0.6047 \\
\hline & No & 566 & $3.40(3.34,3.46)$ & & & 232 & $3.53(3.44,3.62)$ & & \\
\hline \multirow[t]{2}{*}{ Coffee intake } & No & 44 & $3.15(2.95,3.37)$ & 4.713 & 0.0302 & 26 & $3.37(3.11,3.65)$ & 1.865 & 0.1727 \\
\hline & Yes & 961 & $3.37(3.33,3.41)$ & & & 457 & $3.56(3.49,3.63)$ & & \\
\hline \multirow[t]{2}{*}{ Season } & Not winter & 651 & $3.40(3.35,3.45)$ & 6.495 & 0.0110 & 320 & $3.59(3.51,3.67)$ & 2.136 & 0.1445 \\
\hline & Winter & 367 & $3.29(3.22,3.36)$ & & & 170 & $3.49(3.39,3.59)$ & & \\
\hline \multirow[t]{2}{*}{ BMI } & Below median & 504 & $3.27(3.21,3.33)$ & 18.557 & 0.0000 & 243 & $3.46(3.37,3.55)$ & 9.959 & 0.0017 \\
\hline & Above median & 508 & $3.45(3.39,3.51)$ & & & 241 & $3.67(3.58,3.76)$ & & \\
\hline \multirow[t]{2}{*}{ Hypertension } & No & 706 & $3.30(3.25,3.34)$ & 22.896 & 0.0000 & 345 & $3.50(3.43,3.58)$ & 5.978 & 0.0148 \\
\hline & Yes & 312 & $3.52(3.44,3.60)$ & & & 145 & $3.68(3.56,3.79)$ & & \\
\hline \multirow[t]{2}{*}{ Diabetes mellitus } & No & 953 & $3.36(3.31,3.40)$ & 1.260 & 0.2618 & 463 & $3.54(3.47,3.60)$ & 3.615 & 0.0579 \\
\hline & Yes & 51 & $3.47(3.24,3.71)$ & & & 20 & $3.86(3.48,4.27)$ & & \\
\hline \multirow[t]{2}{*}{ History of chest pain } & No & 925 & $3.34(3.30,3.38)$ & 7.254 & 0.0072 & 453 & $3.54(3.48,3.61)$ & 0.724 & 0.3951 \\
\hline & Yes & 74 & $3.57(3.39,3.74)$ & & & 29 & $3.66(3.34,4.02)$ & & \\
\hline \multirow[t]{2}{*}{ CVD history } & No & 933 & $3.34(3.30,3.38)$ & 13.849 & 0.0002 & 447 & $3.51(3.45,3.57)$ & 18.192 & 0.0000 \\
\hline & Yes & 85 & $3.63(3.47,3.80)$ & & & 43 & $4.02(3.75,4.31)$ & & \\
\hline Occupational class & White collar & 642 & $3.31(3.26,3.37)$ & 5.527 & 0.0189 & 299 & $3.50(3.42,3.58)$ & 2.728 & 0.0994 \\
\hline & Blue collar & 238 & $3.44(3.35,3.53)$ & & & 129 & $3.62(3.50,3.76)$ & & \\
\hline Shift work & No & 897 & $3.35(3.31,3.39)$ & 2.348 & 0.1257 & 444 & $3.54(3.47,3.60)$ & 1.484 & 0.2238 \\
\hline & Yes & 108 & $3.46(3.30,3.62)$ & & & 30 & $3.71(3.39,4.05)$ & & \\
\hline Night work & No & 939 & $3.35(3.31,3.39)$ & 6.726 & 0.0096 & 448 & $3.55(3.49,3.62)$ & 0.185 & 0.6675 \\
\hline & Yes & 31 & $3.68(3.33,4.07)$ & & & 13 & $3.47(3.25,3.70)$ & & \\
\hline Overtime work & No & 582 & $3.37(3.32,3.43)$ & 0.340 & 0.5602 & 395 & $3.58(3.51,3.66)$ & 5.786 & 0.0165 \\
\hline & Yes & 423 & $3.35(3.28,3.41)$ & & & 79 & $3.38(3.23,3.54)$ & & \\
\hline Foreperson & Yes & 467 & $3.37(3.31,3.44)$ & 0.371 & 0.5426 & 89 & $3.49(3.33,3.65)$ & 0.780 & 0.3777 \\
\hline & No & 537 & $3.35(3.29,3.40)$ & & & 383 & $3.56(3.49,3.63)$ & & \\
\hline
\end{tabular}



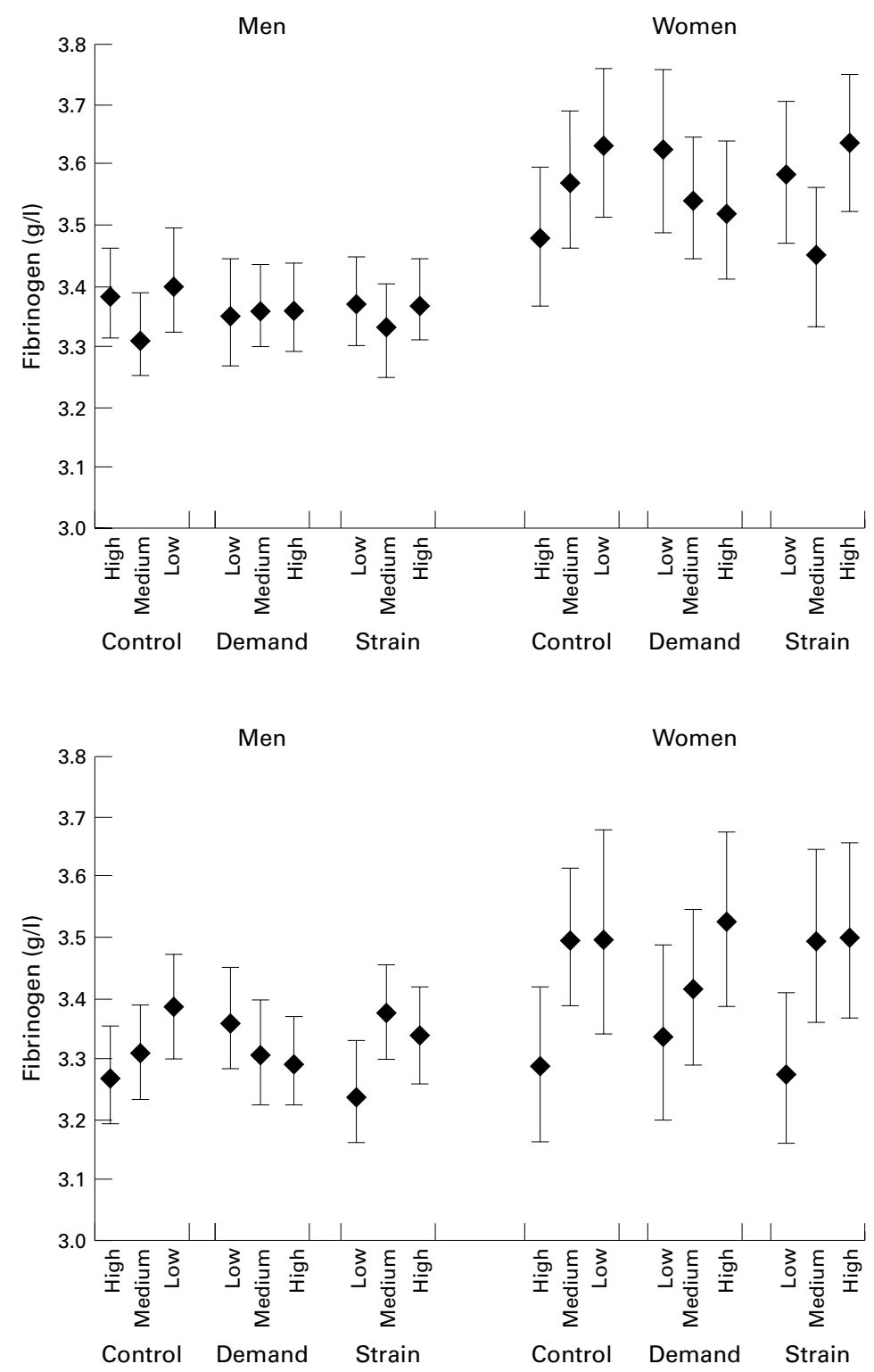

Figure 1 fob characteristics and plasma fibrinogen concentrations in the referents of the SHEEP study, 1992-1994 (geometric means and 95\% confidence intervals). The top panel shows the association between self reported job characteristics and plasma fibrinogen concentrations, and the bottom panel the association between inferred job characteristics and plasma fibrinogen concentrations. Data without adjustments for confounders.

psychological job demands indicator is a two item scale that measures time pressure and psychological demands. ${ }^{23}$ Job strain was defined as the ratio between demands and control. Then, subjects were grouped into three strata of each job characteristics index (low, medium, high demands, control and the demand/control ratio, respectively). The grouping was based on tertiles defined according to the distribution of scores in the total male and female referent working populations, respectively. It should be noted that the occupational titles were only for subjects who were working during the year preceding the examination. Thus the numbers of subjects analysed for self reported job characteristics and for inferred job characteristics were different.

The health examinations took place in the outpatient surgeries of the internal medicine departments at the 10 emergency hospitals.
KEY POINTS

- Measuring job characteristics by means of both subjective and objective methods is considered to be preferable in job stress research.

- Plasma fibrinogen seems to be related to many social and behavioural factors including adverse working conditions.

- Plasma fibrinogen may be one of the underlying mechanisms by which adverse psychosocial job characteristics lead to coronary heart disease.

They were carried out in the morning by a small group of specially trained nurses and comprised measurements of blood pressure, height, body weight as well as blood sampling. Body mass index (BMI) was calculated as weight in kilograms divided by height in metres squared. BMI was divided into two categories on the median of each sex.

After overnight fasting, blood samples were obtained by venous puncture and handled according to prevailing clinical practice for analyses of plasma haemostatic factors. Specimens for analyses for plasma fibrinogen were collected into citric acid treated tube and within three hours separated plasma was frozen at $-70^{\circ} \mathrm{C}$. Plasma fibrinogen was determined with polymerisation time ${ }^{24}$ at one single laboratory, the Department of Clinical Chemistry at the Karolinska Hospital.

\section{STATISTICS}

All analyses were performed separately for men and women. The distribution of plasma fibrinogen concentrations was subjected to natural logarithmic transformation to reduce skewness and kurtosis. Comparison of mean plasma fibrinogen values was performed using analysis of variance without adjustments. To evaluate the independent relation between each job characteristic and plasma fibrinogen concentration, we conducted multiple regression analyses. Logistic regression analyses were performed with setting the category of increased plasma fibrinogen concentration (upper median concentrations; more than 3.3 $\mathrm{g} / 1$ for men and $3.5 \mathrm{~g} / 1$ for women, respectively). Only those covariates found to be related to outcome measures of plasma fibrinogen at a significant level of $\mathrm{p}<0.10$ were included in the multivariate models. Logistic regression analyses were conducted in two ways; age and hospital catchment area were adjusted for and then all the covariates were included as well as age and hospital catchment area.

\section{Results}

The distribution of plasma fibrinogen concentrations was slightly skewed and the concentrations of plasma fibrinogen were significantly higher in women than in men even after age had been adjusted for (geometric means with $95 \%$ confidence intervals $=3.55 \mathrm{~g} / 1$ (3.49, $3.62)$ and $3.36 \mathrm{~g} / 1(3.32,3.40)$, respectively, $F$ $=14.198, \mathrm{p}=0.0000)$. 
Table 1 shows the crude mesures of job characteristics. Both for self reported and inferred scoring, women perceived higher job strain than men.

Table 2 shows plasma fibrinogen concentrations according to sociodemographic and behavioural variables with univariate analyses. Age, educational level, smoking, physical activity, BMI, hypertension, and history of cardiovascular diseases were significantly associated with plasma fibrinogen concentrations both in men and women. Furthermore, marital status, fish intake, coffee intake, season (opposite direction), history of chest pain, occupational class, working condition of frequent night work were associated with plasma fibrinogen concentration in men. Menopause, hormone therapy, alcohol intake, and overwork (opposite direction) were associated with plasma fibrinogen concentration in women. Those who had family history of diseases defined above tended to have higher plasma fibrinogen concentrations than did the respective others but the differences did not reach statistical significance (data not shown).

Figure 1 shows the univariate associations among plasma fibrinogen concentrations and self reported job characteristics and inferred job characteristics. The geometric means and 95\% confidence intervals are shown. Remarkable associations were not indicated between self reported job characteristics and plasma fibrinogen concentrations except for the association in the expected direction between high plasma fibrinogen concentration and low control in women. The associations between inferred job characteristics and plasma fibrinogen concentrations were more consistent. Only the direction of increasing plasma fibrinogen concentrations with decreasing inferred demands in men was in contrast with our expectation. The differences of plasma fibrinogen concentrations were significant among inferred control levels and among inferred strain levels in women $(F=3.242, \mathrm{p}=0.0406$ and $F=$ $3.479, \mathrm{p}=0.0322$, respectively). The differences were, however, not statistically significant among inferred strain levels in men and among self reported strain levels in women $(F=2.777$, $\mathrm{p}=0.0629$ and $F=2.758, \mathrm{p}=0.0645$, respectively).

Table 3 Relative risks (RR) and 95\% confidence intervals (CI) of adverse psychological job characteristics for increased plasma fibrinogen (above median) in referents of the SHEEP study, 1992-1994

\begin{tabular}{lrlll}
\hline Variables & Number & RR $(95 \% \mathrm{CI})^{*}$ & Number & RR $(95 \% \mathrm{CI})+$ \\
\hline Men & & & & \\
$\quad$ Self reported control & 1000 & $1.0(0.8,1.2)$ & 831 & $0.9(0.8,1.2)$ \\
$\quad$ Self reported demand & 1001 & $1.0(0.8,1.2)$ & 829 & $1.1(0.9,1.3)$ \\
$\quad$ Self reported strain & 996 & $1.0(0.9,1.2)$ & 828 & $1.1(0.9,1.4)$ \\
$\quad$ Inferred control & 751 & $1.1(0.9,1.3)$ & 633 & $1.1(0.8,1.4)$ \\
$\quad$ Inferred demand & 751 & $1.0(0.8,1.2)$ & 633 & $1.0(0.8,1.2)$ \\
$\quad$ Inferred strain & 751 & $1.2(1.0,1.5)$ & 633 & $1.2(1.0,1.5)$ \\
Women & & & & \\
$\quad$ Self reported control & 467 & $1.2(0.9,1.5)$ & 412 & $1.3(1.0,1.8)$ \\
$\quad$ Self reported demand & 468 & $0.8(0.7,1.1)$ & 413 & $0.8(0.6,1.0)$ \\
$\quad$ Self reported strain & 463 & $1.0(0.8,1.2)$ & 408 & $0.9(0.7,1.2)$ \\
Inferred control & 273 & $1.3(1.0,1.8)$ & 247 & $1.2(0.8,1.8)$ \\
$\quad$ Inferred demand & 273 & $1.4(1.0,1.9)$ & 247 & $1.5(1.0,2.2)$ \\
$\quad$ Inferred strain & 273 & $1.5(1.1,2.1)$ & 247 & $1.5(1.1,2.2)$ \\
\hline
\end{tabular}

${ }^{\star}$ Adjusted for age and hospital catchment area. †Adjusted for all fibrinogen correlates in univariate analyses.
Table 3 shows the relative risks of job characteristics for increased (above median) plasma fibrinogen concentrations. In women, self reported control was inversely associated with higher concentrations of plasma fibrinogen in the fully adjusted model. However, self reported demand was even negatively associated with higher concentrations of plasma fibrinogen. Self reported strain had almost null relations with increased plasma fibrinogen concentrations in both sexes.

When age and hospital catchment area were adjusted for, inferred strain was significantly associated with increased plasma fibrinogen concentrations in men. The relation remained significant when all the confounding factors were adjusted for. In women, all three inferred models were associated with increased plasma fibrinogen concentration both in age adjusted analyses and when all the covariates had been adjusted for, although the association between inferred control and plasma fibrinogen concentrations did not reach statistical significance in the fully adjusted model.

\section{Discussion}

In this cross sectional analysis, we observed some positive associations between objective job (stressful) characteristics and plasma fibrinogen concentrations particularly among women. In male workers, objective job strain was also associated with higher concentration of plasma fibrinogen. Although we could not find any association between self reported job strain and plasma fibrinogen concentrations, female workers with low self reported job control had higher concentrations of plasma fibrinogen. The associations were relatively weak albeit significant. However, they might be of interest because cardiovascular diseases are prevalent, particularly in Western societies.

Our findings were partly in accordance with those of the Whitehall study II by Brunner and colleagues. ${ }^{11}$ Our findings on "objectively" measured job control in women were similar to those of the Whitehall study. In the Whitehall study II, however, self reported job control was positively associated with plasma fibrinogen concentrations in women. In contrast, low perceived job control was associated with higher concentrations of plasma fibrinogen in the women in our study. The differences in results could be attributable to differences both with regard to the questionnaires and study populations. Furthermore, work related conditions are also different between the two countries particularly with regard to female workers.

The difference in the associations between plasma fibrinogen concentrations and subjective job characteristics on one hand and plasma fibrinogen concentrations and objective job characteristics on the other hand needs to be discussed. Self reported job characteristics and inferred job characteristics are somewhat correlated while they are not identical. Environmental scaling may reflect in a better way the objective situation than does the individually perceived situation by reducing possible bias resulting from the perception of the work situation by the participants. Furthermore, the 
difference could be partly explained by the fact that we used information on occupational title from the year before inclusion in SHEEP. With regard to the sex difference in this study, there was also a practical problem. In male subjects, when job characteristics were defined by means of the highest quartile and this group was compared with the rest, self reported low control as well as inferred low control were associated with significantly increased plasma fibrinogen concentrations even after other confounding variables had been adjusted for. Cut off points for discriminating an increased risk may be different for the sexes.

It should also be noted that the association between job control and plasma fibrinogen was more consistent than the association between psychological demands and plasma fibrinogen. The direction of decreasing plasma fibrinogen concentrations according to the indices of psychological demands (self reported demands for women/inferred demands for men) that were found in this study was in contrast with our expectation, although it did not reach statistical significance. Inferred high psychological demands were not associated with an increased risk of having a first myocardial infarction among male workers in the SHEEP study. ${ }^{16}$ The inferred measures of psychological demands are based upon two questions - one on "tempo" (rush) and one on "psychologically strenuous." The second one-psychologically strenuous - is associated with higher occupational status and may be an indicator of being "in demand" and doing more varied work; low status on the other hand is associated with monotony. ${ }^{25}$ As shown in some recent studies, psychological demands did not necessarily predict CVD. ${ }^{16}{ }^{26}{ }^{27}$ It has been argued that the measurement of psychological demands should be re-evaluated. ${ }^{1627}$

Clearly plasma fibrinogen concentrations seem to be affected by many social, biological, and behavioural factors. In agreement with previous studies, ${ }^{812} 17$ we found significant associations between plasma fibrinogen concentrations and several sociodemographic variables in the univariate analyses. Social class (occupational class and educational level) was shown to be correlated with plasma fibrinogen concentrations as in other studies..$^{10-12}$ The relations with inferred job characteristics, however, remained significant after adjustment for occupational class and educational level. In this study, the division of subjects into blue and white collar as well as into those with high/low education was considered to be the most adequate description of social class.

An interesting finding in this study is the strong relation between reported frequent night work and high plasma fibrinogen concentrations in men. Although this is a result of univariate analysis, this finding suggests that besides bad sociodemographic conditions in general, bad working conditions have an influence on plasma fibrinogen concentrations. In women, the puzzling finding was made that those who reported few overtime work hours had high plasma fibrinogen concentrations. However, within reasonable limits, overtime work may not necessarily lead to a stressful job condition when taking into consideration the high reward that is sometimes the result from overtime work. Because of the small number in the category, we could not see any difference of plasma fibrinogen concentrations according to the excess level of working hours. Obviously the work contents may make a difference and accordingly this finding should be subjected to a deeper analysis.

The cross sectional design does not permit conclusions on the causal relations between job characteristics and plasma fibrinogen concentration. Although many established confounding and mediating factors were considered, we were not able to adjust for some important variables regarding plasma fibrinogen concentration, such as a marker of acute phase reaction (which is for instance reflected in white blood cell counts or in $\mathrm{C}$ reactive protein).${ }^{19}$ Furthermore, differences in genetic predisposition for variations in plasma fibrinogen concentrations could not be taken into account. Hamsten et $a l^{28}$ reported that $51 \%$ of the variance of the plasma fibrinogen concentration was accounted for by genetic heritability. The present population is, however, a fairly homogeneous group of Swedish descent.

In conclusion, our findings suggest that job characteristics particularly measured by means of objective methods are related to plasma fibrinogen concentrations and that this relation is more relevant in female workers.

The authors thank Annika Gustavsson for excellent data management.

Funding: this study was financially supported by the Stockholm Funding: this study was financially supported by the
County and the Swedish Medical Research Council. Conflicts of interest: none.

1 Stone MC, Thorp JM. Plasma fibrinogen-a major coronary risk factor. I R Coll Gen Pract 1985;35:565-9.

2 Meade TW, Mellows S, Brozovic M, et al. Haemostatic function and ischaemic heart disease: principal results of function and ischaemic heart disease: principal results

3 Kannel WB, Wolf PA, Castelli WP, et al. Fibrinogen and risk Kannel WB, Wolf PA, Castelli WP, et al. Fibrinogen and risk
of cardiovascular disease: The Framingham Study. $\mathcal{F} A M A$ 1987;258:1183-6.

4 Yarnell JW, Baker IA, Sweetnam PM, et al. Fibrinogen, viscosity, and white blood cell count are major risk factors for ischemic heart disease. The Caerphilly and Speedwell collaborative heart disease studies. Circulation 1991;83:83644.

5 Kasl SV. The influence of the work environment on cardiovascular health: a historical, conceptual, and methodological perspective. F Occup Health Psychol 1996;1:42-56.

6 Friedman M, Rosenman RH, Carroll V. Changes in the serum cholesterol and blood clotting time in men subjected to cyclic variation of occupational stress. Circulation 1958;17:852-61.

7 Netterstrøm B, Kristensen TS, Damsgaard MT, et al. Job strain and cardiovascular risk factors: a cross sectional study of employed Danish men and women. Br f Ind Med 1991;48:684-9.

8 Folsom AR, Qamhieh HT, Flack JM, et al. Plasma Folsom AR, Qamhieh HT, Flack JM, et al. Plasma
fibrinogen: levels and correlates in young adults. Am $\mathcal{F} E p i-$ demiol 1993;138:1023-36.

9 Davis MC, Matthews KA, Meilahn EN, et al. Are job characteristics related to fibrinogen levels in middle-aged women? Health Psychol 1995;14:310-18

10 Markowe HLJ, Marmot MG, Shipley MJ, et al. Fibrinogen: a possible link between social class and coronary heart disease. BMF 1985;291:1312-14.

11 Brunner E, Davey Smith G, Marmot M, et al. Childhood social circumstances and psychosocial and behavioural factors as determinants of plasma fibrinogen. Lancet 1996; 347:1008-13.

12 Møller L, Kristensen TS. Plasma fibrinogen and ischemic heart disease risk factors. Arterioscler Thromb 1991;11:34450.

13 Mattiasson I, Lindgärde F. The effect of psychosocial stress nd risk factors for ischaemic heart disease on the plasm fibrinogen concentration. F Intern Med 1993;234:45-51. 
14 Ishizaki M, Tsuritani I, Noborisaka Y, et al. Relationship between job stress and plasma fibrinolytic activity in male J15-20.

15 Reuterwall C, Hallqvist J, Ahlbom A, et al. Higher relative but lower absolute risks of myocardial infarction in women than in men: analysis of some major risk factors in the SHEEP study. F Intern Med (in press).

16 Theorell T, Tsutsumi A, Hallqvist J, et al. Decision latitude, job strain and myocardial infarction: a study of working men in Stockholm (Stockholm Heart Epidemiology Program, SHEEP). Am $\mathcal{7}$ Public Health 1998;88:382-8.

17 Iso H, Folsom AR, Sato S, et al. Plasma fibrinogen and its correlates in Japanese and US population samples. Arterioscler Thromb 1993;13:783-90.

18 Bak AAA, Grobbee DE. Coffee, caffeine and hemostasis: a review. Neth f Med 1990;37:242-6.

19 Woodhouse PR, Khaw KT, Plummer M, et al. Seasonal variations of plasma fibrinogen and factor VII activity in the elderly: winter infections and death from cardiovascular disease. Lancet 1994;343:435-9.

20 Statistics Sweden. Swedish socio-economic classification. Stockholm: Statistics Sweden, 1982.

21 Lundberg O. Den ojämlika hälsan. [Doctoral thesis]. Stockholm: Stockholm University, 1990.
22 Theorell T, Perski A, Åkerstedt T, et al. Changes in job strain in relation to changes in physiological state. A longitudinal study. Scand f Work Environ Health 1988;14:18996.

23 Johnson JV, Stewart WF. Measuring work organization exposure over the life course with a job-exposure matrix. Scand $\mathcal{F}$ Work Environ Health 1993;19:21-8.

24 Vermylen C, de Vreker RA, Verstraete M. A rapid enzymatic method for assay of fibrinogen fibrin polymerization time (FTP test). Clin Chim Acta 1963;8:418-24.

25 Hemingway H, Shipley MJ, Stansfeld S, et al. Sickness absence from back pain, psychosocial work characteristics and employment grade among office workers. Scand 7 Work Environ Health 1997;23:121-9.

26 Alterman T, Shekelle RB, Vernon SW, et al. Decision latitude, psychologic demand, job strain, and coronary heart disease in the Western Electric Study. Am $\mathcal{F}$ Epidemiol 1994;139:620-7.

27 Johnson JV, Stewart W, Hall EM, et al. Long-term psychosocial work environment and cardiovascular mortality among Swedish men. Am f Public Health 1996;86: $324-31$

28 Hamsten A, Iselius L, de Faire U, et al. Genetic and cultural inheritance of plasma fibrinogen concentration. Lancet 1987;ii:988-91. 